\title{
Article
}

||||||||||||||||||||||||||||||||||||||||||||

\section{Determination of Uranium in Rocks and Soils of South Cameroon by $\gamma$-ray Spectrometry}

\author{
Jean Félix Beyala AtebA*,**, Pierre Owono AtebA**, \\ Germain Hubert Ben-Bolie**, Henri Ekobena FoudA**, Patrice Ele Abiama**, \\ Clément Roger ABEgA** and Stanislas Mvondo*,** \\ *National Radiation Protection Agency \\ P. O. Box 33732, Yaoundé, Cameroon \\ **Department of Physics, Faculty of Science, University of Yaoundé I \\ P. O. Box 812, Yaoundé, Cameroon \\ Received January 5, 2010
}

\begin{abstract}
Analytical results of uranium concentration in rocks and soils collected in the area of Lolodorf of South Cameroon where a radiometric anomaly had been found by previous investigation are reported. The analysis has been carried out by $\gamma$-ray spectrometry using a Ge detector. Radioactivity concentration of ${ }^{235} \mathrm{U}$ was determined by comparing peak count rates of samples with those of natural uranium standard sample. Radioactivity concentration of ${ }^{238} \mathrm{U}$ was calculated from the ${ }^{235} \mathrm{U}$ radioactivity concentration by assuming that the isotopic composition of ${ }^{235} \mathrm{U}$ is $0.7200 \%$ of natural abundance. Difference of $\gamma$-ray self-absorption between the samples and uranium standard was accurately corrected by using a mass attenuation coefficient of samples and standard measured by using an external $\gamma$-ray source. The radioactivity concentrations in rocks ranged from $0.92 \pm 0.02$ to $228 \pm 14 \mathrm{~Bq} / \mathrm{kg}\left({ }^{235} \mathrm{U}\right)$ and $20 \pm 5$ to $4868 \pm 307 \mathrm{~Bq} / \mathrm{kg}\left({ }^{238} \mathrm{U}\right)$, while radioactivity concentrations in soils ranged from $3 \pm 1$ to $63 \pm 2 \mathrm{~Bq} / \mathrm{kg}\left({ }^{235} \mathrm{U}\right)$ and $71 \pm 19$ to $1346 \pm 38 \mathrm{~Bq} / \mathrm{kg}\left({ }^{(238} \mathrm{U}\right)$. The $\gamma$-ray dose rates in air at $1 \mathrm{~m}$ above the ground surface due to the high uranium concentration in soil samples were ranged from $33 \pm 9$ to $622 \pm 18 \mathrm{nGy} / \mathrm{h}$. The highest uranium concentration of about $0.04 \%$ in rock was found in the analysis. These results show that the uranium content in the studied areas is significantly high and the studied areas have a potential for uranium mining.
\end{abstract}

Key Words : uranium, radioactivity concentration, gamma ray dose rate, gamma ray spectrometry, Ge detector, soil, rock

\section{Introduction}

The Lolodorf area located at the South Cameroon (Fig. 1) was suspected to have uranium ore deposits. The French Office of Geological and Mining Research carried out geological and radiometric studies in this area to evaluate the mineral potential of the location under study from 1978 to $1985^{1)}$. The radiometric study has consisted of helicopter-borne radiometric survey using a portable $\mathrm{NaI}(\mathrm{Tl})$ spec- trometer to identify high uranium abundance area. It was found that the $\gamma$-radiation level of Lolodorf area was relatively higher than the other area. The geological aspect of this study has reported the presence of alkaline syenite which is a coarse-grained intrusive igneous rock of the same general composition as granite but with quartz either absent or present in relatively small amounts $(<5 \%)$. On the other hand, Lolodorf area is in rural district and over $80 \%$ of the population is engaged in agriculture. 


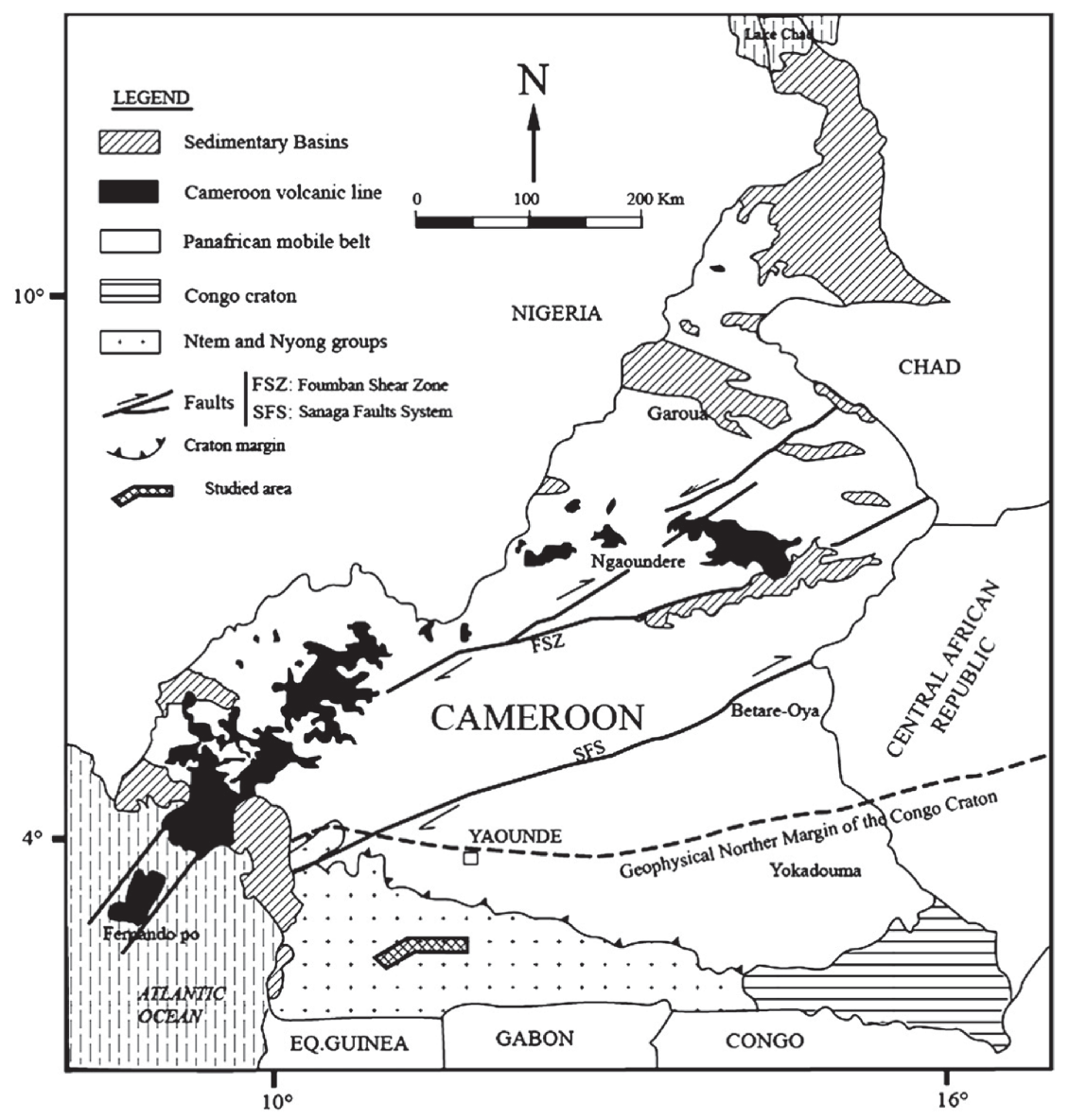

Fig. 1 A map of Cameroon including sampling site of Lolodorf.

The main objective of this study is determination of uranium concentration in rocks and soils in this area to evaluate possibility of uranium mining and external radiation exposures of inhabitants from uranium nuclides and their decay product nuclides of this area.

Since their chemical robustness of rock and soil, $\gamma$-ray spectrometry ${ }^{2)}$ using a Ge detector of non-destructive method was chosen for the analysis among the many analytical methods. Although uranium has 3 radionuclides ${ }^{234} \mathrm{U},{ }^{235} \mathrm{U}$ and ${ }^{238} \mathrm{U}$ in the nature abundance of $0.0055 \%$, $0.7200 \%$ and $99.2745 \%$, respectively, ${ }^{235} \mathrm{U}$ is the most suitable nuclide for the measurement since the other nuclides are low natural abundance or no $\gamma$-ray emission. Decay products of ${ }^{238} \mathrm{U}$ such as ${ }^{234} \mathrm{Th},{ }^{234 \mathrm{~m}} \mathrm{~Pa},{ }^{214} \mathrm{~Pb}$ and ${ }^{214} \mathrm{Bi}$ can also be used for the measurement of uranium, however, radiochemical equilibrium condition of the nuclides in the samples must be corrected. In addition, emanation of ${ }^{222} \mathrm{Rn}$, which is precursor of ${ }^{214} \mathrm{~Pb}$ and ${ }^{214} \mathrm{Bi}$, from sample affects for the measurement of ${ }^{214} \mathrm{~Pb}$ and ${ }^{214} \mathrm{Bi}$. Thus, we selected ${ }^{235} \mathrm{U}$ as the measurement nuclide.

Since ${ }^{235} \mathrm{U}$ emits low energy $\gamma$-rays of less than $200 \mathrm{keV}$, self-absorption of the measurement $\gamma$-rays with sample matrices is significant. The analysis has been performed by correcting 
the sample self-absorption accurately by using a mass attenuation coefficient of the samples and standard measured by an external $\gamma$-ray source method. We report analytical results of ${ }^{235} \mathrm{U}$ and ${ }^{238} \mathrm{U}$ radioactivity concentration in soil and rock samples collected from Lolodorf area of South Cameroon by $\gamma$-ray spectrometry, and $\gamma$-ray dose rates of the area due to ${ }^{238} \mathrm{U}$ calculated from the analytical results of soils.

\section{Experimental}

$2 \cdot 1 \quad$ Sampling and sample preparation

The soil and rock samples were collected from Ngombas and Bikoue regions in Lolodorf area of South Cameroon where uranium and potassium anomalies were found in previous radiometric investigation. A total area of the two sampling regions was 125 and $88 \mathrm{~km}^{2}$ at Ngombas and Bikoue, respectively. The two sampling regions were divided into 7 (Ngombas) and 6(Bikoue) sites of equal area. Each site was $18 \mathrm{~km}^{2}$ and $15 \mathrm{~km}^{2}$ for Ngombas and Bikoue, respectively. The each site was further divided into 5 cells of area $3.5 \mathrm{~km}^{2}$ and $3.0 \mathrm{~km}^{2}$ for Ngombas and Bikoue, respectively. A $500 \mathrm{~g}$ of soil was collected from the center of each cell, and then the 5 samples of same site were mixed well. A $500 \mathrm{~g}$ of soil was taken from the mixture for the analysis. A $500 \mathrm{~g}$ of rock was collected at the center of the sampling site when the accessibility allows it. However, only soils were collected in the sampling sites at No. 2 (Ng-02), $3(\mathrm{Ng}-03)$ and $5(\mathrm{Ng}-05)$ of Ngombas where rock does not exist on the surface. All sampling site centers are located in inhabited or agricultural area and are shown in the Fig. 2. Contaminated vegetation and organic matter were removed from the collected samples. Rock and soil samples from a total of 13 sites were collected as shown in the figure.

All samples were brought to the laboratory and dried overnight at a temperature of $250^{\circ} \mathrm{C}$.

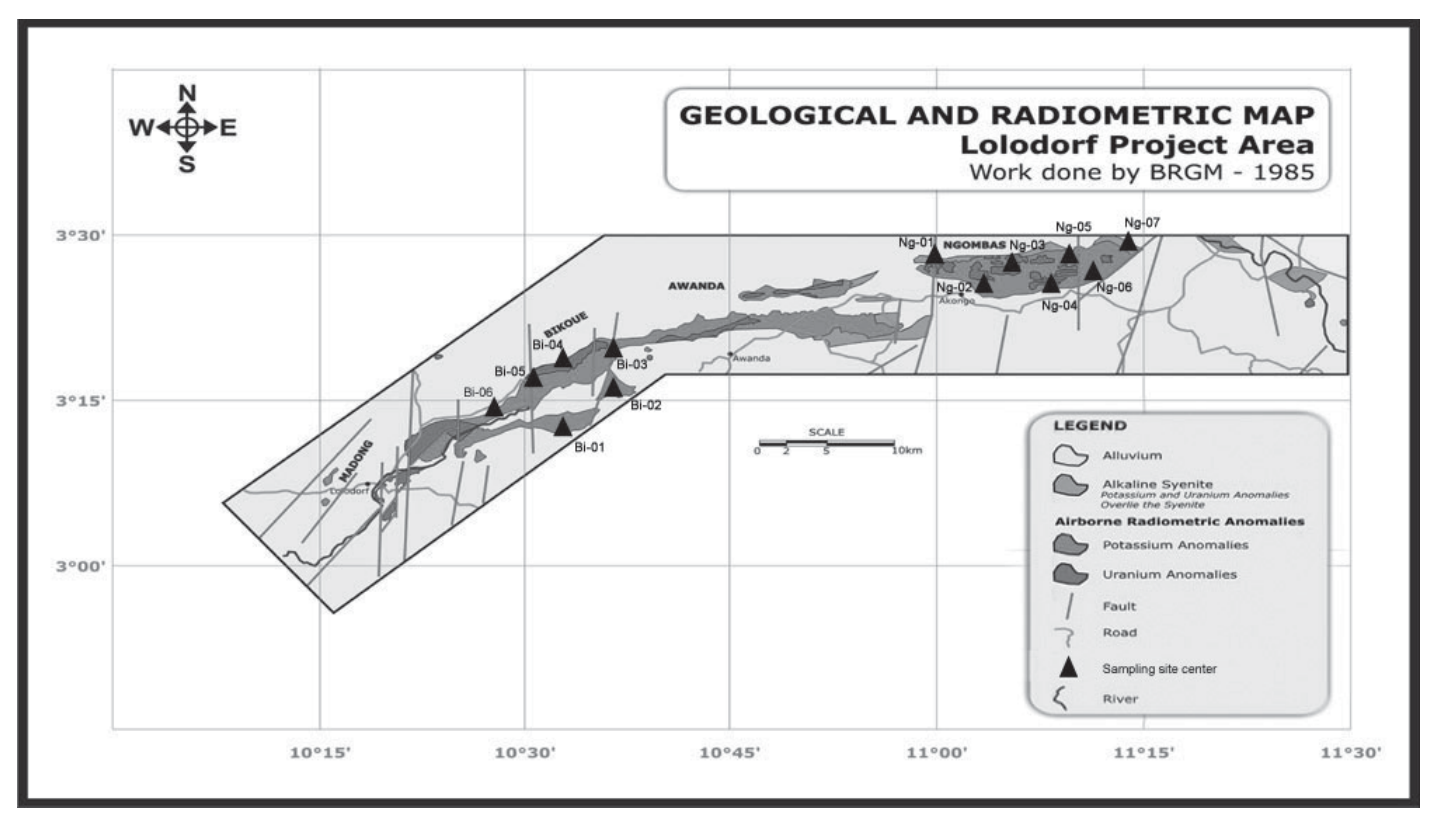

Fig. 2 A map of sampling site of Lolodorf in Cameroon.

The sampling sites show with filled triangles together with codes on the map. 
After cooling, the rock samples were crushed into small pieces and then homogenized. The samples were taken by weighing $110 \mathrm{~g}$ and $130 \mathrm{~g}$ on average for soil and rock, respectively, into a cylinder shaped polystyrene sample container of $86.0 \mathrm{~mL}$ volume and $55.5 \mathrm{~mm}$ internal diameter.

\section{$2 \cdot 2$ Standard samples}

A natural uranium standard and uranium ore standard samples prepared by Dr. Yonezawa of IAEA are used for standardization of uranium contents and to check accuracy of the analytical method, respectively. A natural uranium standard solution $\left({ }^{235} \mathrm{U}: 9.644 \mathrm{~Bq},{ }^{238} \mathrm{U}\right.$ : 209.5 Bq) was prepared from Natural Uranium Radioactivity Standard (NIST SRM-4321C) by diluting with $2 \mathrm{M} \mathrm{HCl}$ into a sample container same as the samples. A uranium ore standard sample was prepared by weighing $105.47136 \mathrm{~g}$ (dry weight) of Reference Materials of Uranium Ore (IAEA-RGU-1) into the same type of sample container.

\section{$2 \cdot 3 \quad \gamma$-ray spectrometer}

A $\gamma$-ray spectrometer consisted with an $n$ type Ge detector (CANBERRA model GR3019) and a multi-channel analyzer (CANBERRA Inspector 2000) was used for the measurement. The energy resolution of $1332.5 \mathrm{keV} \gamma$-ray line from ${ }^{60} \mathrm{Co}$ was found to be $1.85 \mathrm{keV}$ at full width of half-maximum (FWHM) with the relative efficiency of $34.9 \%$. The detector was shielded with lead shield (CANBERRA model 777) with $1 \mathrm{~mm}$ thick $\mathrm{Sn}$ and $1.5 \mathrm{~mm}$ thick $\mathrm{Cu}$ graded liner of the inside to absorb characteristic Xrays of $\mathrm{Pb} . \gamma$-ray energy range was adjusted to $0-2000 \mathrm{keV}$ and calibrated using a mixed $\gamma$ nuclides source of ${ }^{241} \mathrm{Am},{ }^{109} \mathrm{Cd},{ }^{57} \mathrm{Co},{ }^{139} \mathrm{Ce},{ }^{137} \mathrm{Cs}$, ${ }^{88} \mathrm{Y}$ and ${ }^{60} \mathrm{Co}$. Stability of energy resolution, de- tection efficiency and peak position of the spectrometer were checked by measuring a point source of ${ }^{152} \mathrm{Eu}$ for 1200 seconds before and after measurement of the samples and standards. The rock and soil samples were measured for 16 and 6 hours, respectively. The obtained $\gamma$ ray spectra were analyzed by a $\gamma$-ray spectrum analysis program CANBERRA Genie 2000 .

$2 \cdot 4$ Measurement of mass attenuation coefficient of the samples for self-absorption correction

The source is set at the top of the sample container of the sample using a stand-alone source support, and then $\gamma$-ray spectrum is measured at identical position of the sample measurement for a period until interested peak height becomes larger than ten thousand counts. Same measurement is carried out for an empty sample container. A linear attenuation coefficient $\mu$ is obtained from peak area of major $\gamma$-ray lines of ${ }^{210} \mathrm{~Pb},{ }^{133} \mathrm{Ba}$ and ${ }^{152} \mathrm{Eu}$ for sample and empty container using equation(1),

$$
\mu=\frac{\ln \left(R_{s} / R_{0}\right)}{-h}
$$

where $R_{s}$ is peak count rates of a sample, $R_{0}$ is peak count rate of an empty container, $h$ is sample height $(\mathrm{cm})$ in this case $3.6 \mathrm{~cm}$. When sample has identical energy $\gamma$-ray peak with the external $\gamma$-ray source in a spectrum, $\gamma$-ray peak counts of the sample must be subtracted from peak counts of external $\gamma$-ray source spectrum of the sample. A mass attenuation coefficient $\mu_{m}$ is obtained dividing the linear attenuation coefficient by a density $\rho\left(\mathrm{g} / \mathrm{cm}^{3}\right)$ of the sample. 

by $\gamma$-ray spectrometry

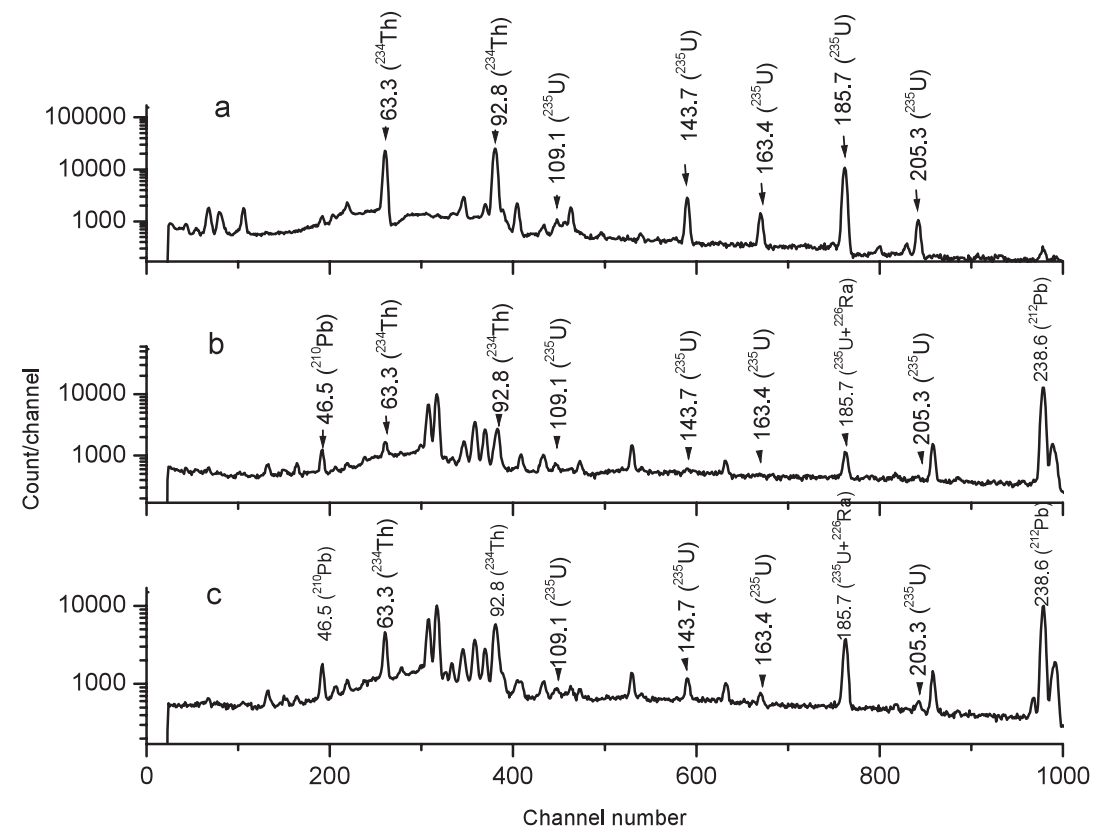

Fig. $3 \gamma$-ray spectra of rock and soil samples compared with natural uranium standard.

a: Natural uranium standard sample

b : Soil sample Bi-01 collected from Bikoue

c : Rock sample Ng-01 collected from Ngombas

\section{Results and discussion}

\section{$3 \cdot 1 \quad \gamma$-ray spectrum of the samples}

$\gamma$-ray spectra at low energy region of rock, soil and uranium standard samples are shown in Fig. 3. $\gamma$-ray peaks of 109.1, 143.7, 163.4, 185.7 and $205.3 \mathrm{keV}$ from ${ }^{235} \mathrm{U}$ together with $\gamma$-rays from decay products of ${ }^{235} \mathrm{U},{ }^{238} \mathrm{U}$ and ${ }^{232} \mathrm{Th}$, and decay $\gamma$-rays from ${ }^{40} \mathrm{~K}$ were detected from the samples. Determination of uranium radioactivity concentration by $\gamma$-ray spectrometry has been carried out by measuring either direct $\gamma$-rays from ${ }^{235} \mathrm{U}$ or decay $\gamma$-rays from ${ }^{234} \mathrm{Th}$ (half-life : 24.10 day), ${ }^{234} \mathrm{~Pa}$ (half-life $: 6.75 \mathrm{~h}$ ) or ${ }^{234 \mathrm{~m}} \mathrm{~Pa}$ (half-life $: 1.17 \mathrm{~min}$ ), which are decay products of ${ }^{238} \mathrm{U}$ since ${ }^{238} \mathrm{U}$ has no direct $\gamma$-ray emission. However, a method which measuring $\gamma$-rays from decay products of ${ }^{238} \mathrm{U}$ has to be measured after stand for more than one month to be radio-equilibrium of the measurement nuclides and ${ }^{238} \mathrm{U}$. Thus we selected the method which measures direct $\gamma$-rays from ${ }^{235} \mathrm{U}$, for the analysis.

Decay $\gamma$-rays of ${ }^{235} \mathrm{U}$ with high emission probability shown in the parentheses are 185.7 (57.2\%), 143.5(10.98\%), $163.3(5.08 \%), 205.3$ (5.01\%) and $109.2(1.54 \%) \mathrm{keV}$. Although 185.7 $\mathrm{keV} \gamma$-ray is the highest intensity, it cannot be used for the analysis due to spectral interference with $186.2 \mathrm{keV} \gamma$-ray of ${ }^{226} \mathrm{Ra}$. Thus we used $\gamma$-rays of $143.5,205.3$ and $109.2 \mathrm{keV}$ for the analysis. Since variation of the analytical results by $163.3 \mathrm{keV} \gamma$-ray is larger than that of the other $\gamma$-rays, this $\gamma$-ray peak was not used for the analysis. Radioactivity concentration of ${ }^{238} \mathrm{U}$ was calculated from that of ${ }^{235} \mathrm{U}$ by assum- 
ing isotopic composition of ${ }^{235} \mathrm{U}$ and ${ }^{238} \mathrm{U}$ in natural abundance.

$3 \cdot 2 \quad \gamma$-ray self-absorption correction of the samples

A uranium $2 \mathrm{M} \mathrm{HCl}$ solution was used as a standard for the analysis. On the other hand, $\gamma$-ray absorption between samples and standard is so diverse because of their differences in density and chemical composition. Soil and rock samples have higher density than standard and are consisted with elements of higher atomic weight such as $\mathrm{Si}, \mathrm{Al}$ and $\mathrm{Fe}$ than the standard. Thus self-absorption difference of $\gamma$-rays between

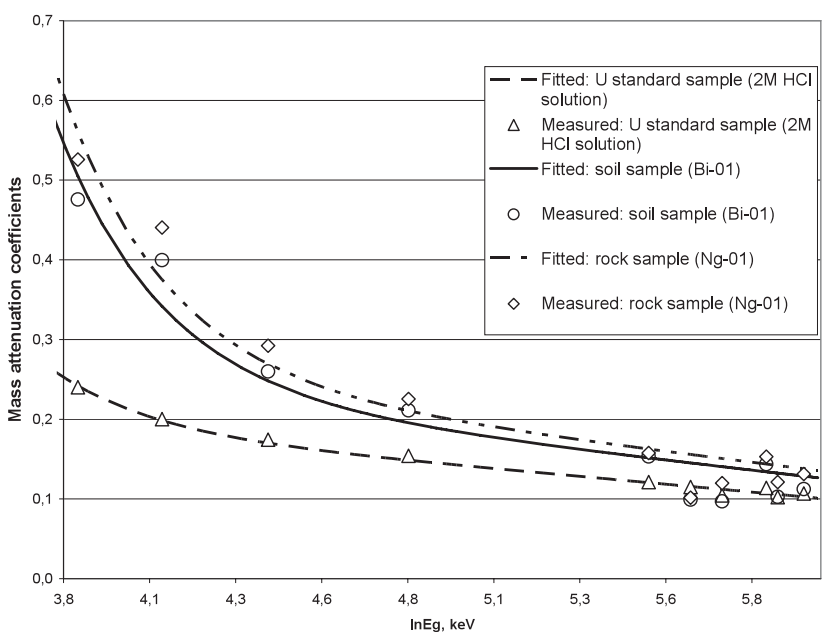

Fig. 4 An example of calculated and measured mass attenuation coefficients of uranium standard sample (2M HCl solution), soil sample (Bi-01) and rock sample (Ng-01).

The horizontal axis show from $\ln 3.8(44.7 \mathrm{keV})$ to $\ln 6.0$ $(403.4 \mathrm{keV})$.

sample and standard, especially at

low energy region is significant. Furthermore, $\gamma$-ray self-absorption among the samples is not identical due to differences of density and sample amounts. The self-absorption of $\gamma$-rays in samples and standard is accurately corrected by a method developed by Yonezawa ${ }^{3)}$. The method is based on a correction using correction factors for $\gamma$-rays which are obtained from experimentally measured mass attenuation coefficients of the samples and standards.

The self-absorption correction factor $C_{A b}$ for a sample at measurement $\gamma$-ray energy relative to the standard is obtained from equation (2),

$$
C_{A b}=\frac{\left(\mu_{m}\right)_{c} \rho_{c} 1-e^{-\left(\mu_{m}\right)_{s} \rho_{s} h}}{\left(\mu_{m}\right)_{s} \rho_{s} 1-e^{-\left(\mu_{m}\right)_{c} \rho_{c} h}}
$$

where $\left(\mu_{m}\right)_{s}$ and $\left(\mu_{m}\right)_{c}$ are mass attenuation coefficients for sample and chemical standard, respectively, at measurement $\gamma$-ray energy, $\rho$ is density $\left(\mathrm{g} / \mathrm{cm}^{3}\right), h$ is sample height $(\mathrm{cm})$, in this case $3.6 \mathrm{~cm}$, and subscripts $s$ and $c$ stand

for sample and chemical standard, respectively. The $\left(\mu_{m}\right)_{c}$ and $\left(\mu_{m}\right)_{s}$ for the measurement $\gamma$ ray are calculated by using the following equation (3),

$$
\begin{aligned}
& \mu_{m}(E, Z)=A(Z) \cdot E^{3.5}+B(Z) \cdot \\
& \quad \exp \left\{0.408(\ln E)-0.066(\ln E)^{2}\right\}
\end{aligned}
$$

where $A(Z)$ and $B(Z)$ are obtained from the least square fitting of experimentally measured mass attenuation coefficients to equation (3), $E$ is measurement $\gamma$-ray energy $(\mathrm{keV})$ and $Z$ is an average atomic number of the sample. The equation(3) was obtained experimentally by Satoh et al. $^{4)}$. The input data of mass attenuation coefficients of samples and standards for equation(3) were obtained experimentally by using an external $\gamma$-ray source method according to Gilmore ${ }^{2)}$. A mixed radionuclide point source of ${ }^{210} \mathrm{~Pb}_{-}{ }^{133} \mathrm{Ba}^{-152} \mathrm{Eu}$ was used as the $\gamma$-ray source. Detail of the correction method will be described elsewhere ${ }^{3)}$.

Figure 4 shows a plot of experimentally ob- 


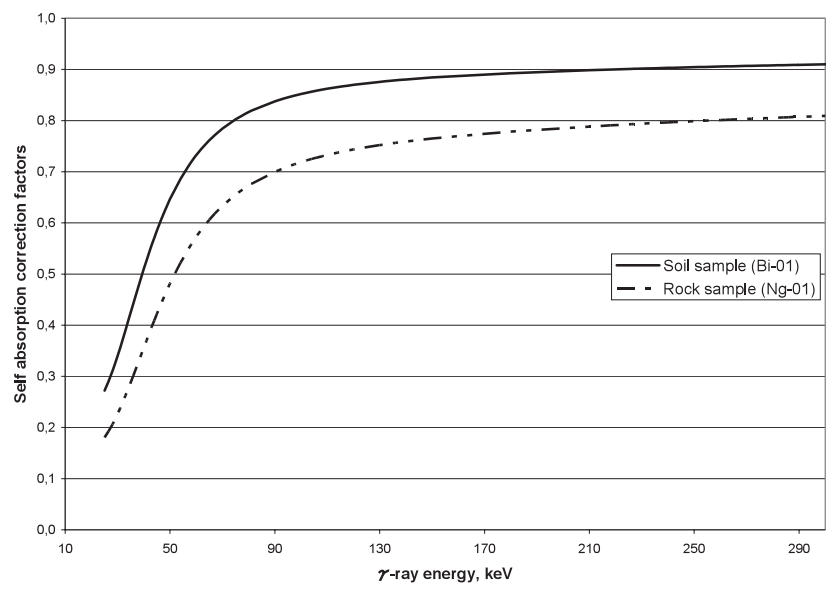

Fig. 5 An example of sample self-absorption correction factors of soil sample (Bi-01) and rock sample (Ng-01). tained mass attenuation coefficients and fitted curves to equation(3) of uranium standard (2M HCl solution), soil sample(Bi-01) and rock sample (Ng-01). Figure 5 is a plot of self absorption correction factors for soil sample(Bi-01) and rock sample (Ng-01) which obtained from the equation (2).

\section{$3 \cdot 3$ Analytical results of the reference ma- terial}

A reference material of Uranium Ore (IAEARGU-1) was analyzed to evaluate accuracy of the presented method. The analytical results are tabulated in Table 1 together with IAEA reference values ${ }^{5), 6)}$. The analytical results of radioactivity concentration of ${ }^{235} \mathrm{U}$ and ${ }^{238} \mathrm{U}$, and elemental uranium concentrations of the present method are in agreement within $4 \%$.
$3 \cdot 4$ Analytical result of rock and soil samples

Analytical results of radioactivity concentration of ${ }^{235} \mathrm{U}$ and ${ }^{238} \mathrm{U}$ and uranium concentration in 11 rock samples and 13 soil samples are listed in Table 2. The table shows analytical results and their average values. The ${ }^{235} \mathrm{U}$ radioactivity concentrations in the table are average of those obtained from 109.1, 143.7 and $205.3 \mathrm{keV}$ $\gamma$-ray lines. Average values and corresponding standard deviation of all rock and soil samples are shown in the table as well.

The highest uranium concentrations in rocks are $104 \pm 9$ and $2204 \pm 194 \mathrm{~Bq} / \mathrm{kg}$ for ${ }^{235} \mathrm{U}$ and ${ }^{238} \mathrm{U}$, respectively, and $179 \pm 16 \mathrm{mg} / \mathrm{kg}$ for $\mathrm{U}$ in the Bikoue region. In the Ngombas region, these values are $228 \pm 14$ and $4868 \pm 307 \mathrm{~Bq} / \mathrm{kg}$ for ${ }^{235} \mathrm{U}$ and ${ }^{238} \mathrm{U}$, respectively, and $395 \pm 23 \mathrm{mg}$ / $\mathrm{kg}$ for $\mathrm{U}$. The highest mass concentrations of $\mathrm{U}$ are equivalent to $0.02 \%$ and $0.04 \%$ for the Bikoue and Ngombas regions, respectively, and they suggest that the studied area has a high possibility of uranium deposit. Further geological investigation is desired for uranium mining.

Due to the high uranium concentration of rocks in the studied area, the highest uranium concentrations in soils are $63 \pm 2$ and $1346 \pm 38$ $\mathrm{Bq} / \mathrm{kg}$ for ${ }^{235} \mathrm{U}$ and ${ }^{238} \mathrm{U}$, respectively, and $110 \pm$ $3 \mathrm{mg} / \mathrm{kg}$ for $\mathrm{U}$ in Bikoue while these values are

Table 1 Analytical results of uranium ore reference material(IAEA-RGU-1)

\begin{tabular}{cccc}
\hline & Obtained value $^{*}$ & IAEA reference value & Deviation, \% \\
\hline${ }^{235} \mathrm{U}, \mathrm{Bq} / \mathrm{kg}$ & $235 \pm 13$ & $228 \pm 2$ & +3 \\
${ }^{238} \mathrm{U}, \mathrm{Bq} / \mathrm{kg}$ & $5149 \pm 190$ & $4940 \pm 30$ & +4 \\
Elemental U, $\mathrm{mg} / \mathrm{kg}$ & $415 \pm 17$ & $400 \pm 2$ & +4 \\
\hline
\end{tabular}

${ }^{*}$ Uncertainty show standard deviations of the $r$-ray counts. 
Table 2 Analytical results of rock and soil samples

\begin{tabular}{ccccccc}
\hline Sampling & \multicolumn{5}{c}{ Rock } \\
\cline { 2 - 6 } site* & ${ }^{235} \mathrm{U}, \mathrm{Bq} / \mathrm{kg}$ & ${ }^{238} \mathrm{U}, \mathrm{Bq} / \mathrm{kg}$ & $\mathrm{U}, \mathrm{mg} / \mathrm{kg}$ & ${ }^{235} \mathrm{U}, \mathrm{Bq} / \mathrm{kg}$ & ${ }^{238} \mathrm{U}, \mathrm{Bq} / \mathrm{kg}$ & $\mathrm{U}, \mathrm{mg} / \mathrm{kg}$ \\
\hline Bi-01 & $41 \pm 5$ & $863 \pm 113$ & $71 \pm 9$ & $23 \pm 3$ & $496 \pm 55$ & $40 \pm 4$ \\
$\mathrm{Bi}-02$ & $0.92 \pm 0.20$ & $20 \pm 5$ & $2.1 \pm 0.4$ & $29 \pm 3$ & $628 \pm 55$ & $51 \pm 4$ \\
$\mathrm{Bi}-03$ & $9 \pm 1$ & $186 \pm 29$ & $15 \pm 2$ & $6 \pm 1$ & $121 \pm 28$ & $10 \pm 2$ \\
$\mathrm{Bi}-04$ & $104 \pm 9$ & $2204 \pm 194$ & $179 \pm 16$ & $36 \pm 4$ & $767 \pm 76$ & $62 \pm 6$ \\
$\mathrm{Bi}-05$ & $76 \pm 3$ & $1625 \pm 80$ & $132 \pm 6$ & $63 \pm 2$ & $1346 \pm 38$ & $110 \pm 3$ \\
$\mathrm{Bi}-06$ & $1.2 \pm 0.1$ & $25 \pm 3$ & $2.0 \pm 0.3$ & $29 \pm 1$ & $621 \pm 27$ & $50 \pm 2$ \\
\hline $\mathrm{Ng}-01$ & $76 \pm 7$ & $1628 \pm 148$ & $133 \pm 12$ & $21 \pm 3$ & $446 \pm 55$ & $36 \pm 4$ \\
$\mathrm{Ng}-02$ & - & - & - & $7 \pm 2$ & $159 \pm 50$ & $13 \pm 4$ \\
$\mathrm{Ng}-03$ & - & - & - & $3 \pm 1$ & $71 \pm 19$ & $6 \pm 1$ \\
$\mathrm{Ng}-04$ & $228 \pm 14$ & $4868 \pm 307$ & $395 \pm 23$ & $3 \pm 1$ & $72 \pm 23$ & $6 \pm 2$ \\
$\mathrm{Ng}-05$ & - & - & - & $4 \pm 1$ & $74 \pm 19$ & $6 \pm 1$ \\
$\mathrm{Ng}-06$ & $27 \pm 4$ & $584 \pm 82$ & $47 \pm 7$ & $18 \pm 1$ & $377 \pm 28$ & $31 \pm 2$ \\
$\mathrm{Ng}-07$ & $86 \pm 8$ & $1829 \pm 161$ & $140 \pm 13$ & $31 \pm 3$ & $668 \pm 63$ & $54 \pm 5$ \\
\hline Mean & $\mathbf{6 3} \pm \mathbf{7 2}$ & $\mathbf{1 3 8 3} \pm \mathbf{1 4 6 0}$ & $\mathbf{1 1 2} \pm \mathbf{1 1 8}$ & $\mathbf{2 1 \pm \mathbf { 1 7 }}$ & $\mathbf{4 5 0 \pm 3 7 0}$ & $\mathbf{3 7 \pm 3 0}$ \\
\hline
\end{tabular}

*The codes " $\mathrm{Bi}$ " and " $\mathrm{Ng}^{\text {" }}$ mean Bikoue and Ngombas, respectively, of sampling regions.

Uncertainties show standard deviations of the $r$-ray counts.

$31 \pm 3$ and $668 \pm 63 \mathrm{~Bq} / \mathrm{kg}$ for ${ }^{235} \mathrm{U}$ and ${ }^{238} \mathrm{U}$, respectively, and $54 \pm 5 \mathrm{mg} / \mathrm{kg}$ for $\mathrm{U}$ in Ngombas. The uranium concentration of the Bikoue region is higher than that of the Ngombas region.

\section{$3 \cdot 5 \quad \gamma$-ray dose rate}

About 45 thousand people are living in the Lolodorf area and about $80 \%$ of the population is engaged in agriculture. Since soil contains high uranium concentration in the area $(63 \pm 2$ and $1346 \pm 38 \mathrm{~Bq} / \mathrm{kg}$ for ${ }^{235} \mathrm{U}$ and ${ }^{238} \mathrm{U}$, respectively, in Bikoue and $31 \pm 3$ and $668 \pm 63 \mathrm{~Bq} / \mathrm{kg}$ for ${ }^{235} \mathrm{U}$ and ${ }^{238} \mathrm{U}$, respectively, in Ngombas), radiation dose exposure of the inhabitants must be evaluated. Thus, $\gamma$-ray dose rate $(\mathrm{nGy} / \mathrm{h})$ at $1 \mathrm{~m}$ high was calculated using the conversion dose coefficient of ${ }^{238} \mathrm{U}\left(0.462 \mathrm{nGy} / \mathrm{h}^{-1}\right.$ per $\left.\mathrm{Bq} / \mathrm{kg}^{-1}\right)^{7,8)}$ and ${ }^{238} \mathrm{U}$ concentration $(\mathrm{Bq} / \mathrm{kg})$ in soil samples. The results are shown in Table 3. The $\gamma$-ray dose rate at $1 \mathrm{~m}$ above the ground surface of Bikoue region is higher than that of Ngombas region since their higher uranium concentrations. Moreover, average $\gamma$-ray dose rate $208 \pm 171 \mathrm{nGy} / \mathrm{h}$ at $1 \mathrm{~m}$ height is higher than the recommended maximum value 57 $\mathrm{nGy} / \mathrm{h}^{9)}$ which takes into account the absorbed dose rate due to ${ }^{238} \mathrm{U},{ }^{232} \mathrm{Th}$ and ${ }^{40} \mathrm{~K}$. Table 4 shows comparison of uranium concentration in soils and $\gamma$-ray dose rate which calculated from the uranium concentration in all over the world ${ }^{8}$. The uranium concentration and $\gamma$-ray dose rate of the Lolodorf area are higher than those of the other area in the world. Further study on health impact of the high $\gamma$-ray dose rate to inhabitants of this area is desired.

\section{Conclusions}

Radioactivity concentrations of uranium nuclides in rocks and soils collected from Lolodorf area in South Cameroon where radiation anomaly had been confirmed in previous investiga- 
Oct. 2011 J. F. Beyala Ateba et al. : Determination of uranium in rocks and soils of South Cameroon by $\gamma$-ray spectrometry

Table $3 \quad \gamma$-ray dose rates in air at $1 \mathrm{~m}$ above the ground of the analyzed soil sample areas

\begin{tabular}{cc}
\hline Sapling site & $\begin{array}{c}r \text {-ray absorbed dose rate in } \\
\text { air, nGy/h }\end{array}$ \\
\hline Bi-01 & $229 \pm 26$ \\
Bi-02 & $290 \pm 26$ \\
Bi-03 & $56 \pm 13$ \\
Bi-04 & $354 \pm 35$ \\
Bi-05 & $622 \pm 18$ \\
Bi-06 & $287 \pm 13$ \\
Ng-01 & $206 \pm 26$ \\
Ng-02 & $74 \pm 23$ \\
Ng-03 & $33 \pm 9$ \\
Ng-04 & $33 \pm 11$ \\
Ng-05 & $34 \pm 9$ \\
Ng-06 & $174 \pm 13$ \\
Ng-07 & $309 \pm 29$ \\
Mean & $\mathbf{2 0 8 \pm 1 7 1}$ \\
\hline
\end{tabular}

*The codes "Bi" and " $\mathrm{Ng}^{\text {" }}$ mean sampling sites Bikoue and Ngombas, respectively. Uncertainties show standard deviation of the $r$-ray counts.

Table 4 Comparison of $\gamma$-ray dose rate among the world due to ${ }^{238} \mathrm{U}$

\begin{tabular}{ccc}
\hline Locality & $\begin{array}{c}{ }^{238} \mathrm{U} \text { concentration } \\
\left(\mathrm{Bq} / \mathrm{kg}^{-1}\right)\end{array}$ & $\begin{array}{c}\gamma \text {-ray dose rate in air } \\
\left(\mathrm{nGy} / \mathrm{h}^{-1}\right)\end{array}$ \\
\hline China & 33 & 16 \\
Hong Kong & 84 & 39 \\
Costa Rica & 46 & 22 \\
United states & 35 & 17 \\
Thailand & 114 & 53 \\
India & 29 & 14 \\
Croatia & 110 & 51 \\
Portugal & 49 & 23 \\
\hline Lolodorf in Cameroon & $\mathbf{4 5 0} \pm \mathbf{3 7 0}$ & $\mathbf{2 0 8} \pm \mathbf{1 7 1}$ \\
\hline The ${ }^{238} \mathrm{U}$ concentrations and their $r$-ray dose rate cited from UNSCEAR ${ }^{8)}$
\end{tabular}

tion has been determined by $\gamma$-ray spectrometry. The highest uranium concentration of 179 $\mathrm{mg} / \mathrm{kg}(0.0179 \%)$ in Bikoue and $395 \mathrm{mg} / \mathrm{kg}$ $(0.0395 \%)$ in Ngomba regions were detected and they suggest that the area has high possibility of uranium deposit. Due to high uranium concentration in rocks of this area, average uranium concentration in soils of $37 \mathrm{mg} / \mathrm{kg}$, is high and $\gamma$-ray dose rate at $1 \mathrm{~m}$ height due to ${ }^{238} \mathrm{U}$ series radio-nuclides of the area is higher than the other area in the world. Further stud- ies are required on geological investigation for uranium mining and on health impact of the high $\gamma$-ray dose rate to inhabitants of this area.

\section{Acknowledgments}

The present work has been carried out at the IAEA Department of Nuclear Sciences and Applications, Physics, Chemistry and Instrumentation Laboratory in Seibersdorf. First of all, the authors would like to thank the supervisors, Dr. Chushiro Yonezawa and Dr. Gyula 
Kis-Benedek, IAEA staff members, for their continuous efforts and scientific guidance during this work. The authors would also like to express their gratitude to the colleagues for their generous inputs and scientific discussions.

\section{References}

1) Maurizot, P., Abessolo, A., Feybesse, J. L., Johan, V. and Lecomte, $\mathrm{P}$., Etude et prospection minière du Sud-Ouest Cameroun, Synthèse des travaux du BGRM, de 1978 à 1985 (1986)

2) Gilmore, G., Practical Gamma-Ray Spectrometry Second Edition, Wiley, Chichester (2008)

3) Yonezawa, C., Unpublished work in 2008

4) Satoh, K., Ohashi, N., Higuchi, H. and Noguchi, M., Determination of attenuation coefficient for selfabsorption correction in routine gamma-ray spectrometry of environmental bulk sample, $J$. Radioanal. Nucl. Chem., 84, 431-440 (1984)

5) IAEA, Preparation of Gamma-ray Spectrometry Reference Materials of RGU-1, RGTh-1 and RGK1, Report-IAEA/RL/148, Vienna (1987)

6) IAEA, IAEA Analytical Quality Control Services Reference Materials Catalogue 2004-2005, p.22 (2004)

7) Saito, K. and Jacob, P., Gamma ray fields in the air due to sources in the ground, Radiat. Prot. Dosm., 58, 29-45 (1995)

8) United Nations Scientific Committee on the Effects of Atomic Radiation, UNSCEAR 2000 Report Vol. I, 115-116 (2000)

9) United Nations Scientific Committee on the Effects of Atomic Radiation, UNSCEAR 1993 Report, Annex A, 44-45 (1993) 